\title{
Riding the equality wave: Generalising public support for a more inclusive society
}

Although debate on social inclusion issues continues to be polarising, with loud voices eschewing or espousing 'political correctness' and the need for social change, there are recent indications both in Australia and around the world that citizens are demanding greater equality and opportunities for all. Certainly, the public vote for marriage equality signalled much positivity in Australia in response to the strength of the vote and the total number who participated. Indeed, the need to legislate for wider human rights protections was raised in the subsequent political jostling that preceded the enactment of marriage equality legislation (Gribbin, 2017). That this led to more discussion of whether a Bill of Rights (or similar) was needed for Australians was most unexpected. Furthermore, issues relating to gender equality and equal pay in Australia continue to gain more traction, assisted in part by some recent, well publicised cases (for example, Stuart, 2017). Internationally, the social movement to end sexual abuse and harassment, following the exposure of high profile cases in the entertainment industry, politics, and sport, has become a juggernaut. The leaking of information detailing secretive off-shore, tax avoidance arrangements of the world's elite and multinational companies, as most recently reflected in the widespread reporting of 'Paradise papers' (for example, Garside, 2017) provides further support for the idea that there is growing intolerance of inequalities and power imbalances. To highlight these issues in isolation, however, masks the true complexity and scale of the efforts required to affect real change and the numerous challenges that still need to be addressed, both in Australia and across the world. Notable examples include the failure to recognise the 'Uluru Statement from the Heart' to progress recognition of first Australians, and the treatment of refugee and asylum seekers internationally. Despite some evidence indicating there are structural determinants of more inclusive attitudes at the population level, for instance, cognitive ability, social status and education (for example, Perales, 2017; Schoon, Cheng, Gale, Batty, \& Deary, 2010), the challenge for researchers and practitioners alike is how do we build on, expand and generalise inclusive behaviours, policy, and practices for the advancement of other social justice issues?

This edition of the Journal of Social Inclusion highlights the efforts of Australian researchers who have examined social inclusion/exclusion issues as they relate to people with disabilities (and their families), younger people, Aboriginal and Torres Strait Islander peoples, second generation Samoan Australians and asylum seekers and refugees. The resulting contributions to the analysis of existing literature and/or provision of new insights and ways of practising should inform decision-making, further research, and continuing service improvement activities. Although, Australia is considered a more inclusive society in the global context, this issue demonstrates some of the domestic challenges that still need to be addressed if we are to achieve real social change and reduce inequalities.

We begin this issue with the results of a systematic review undertaken to identify how social inclusion for people with disabilities has been conceptualised or represented in policy and practice related research in Australia. In acknowledging some of the biases or gaps in the literature, the resulting themes, as identified by Gooding, Anderson and McVilly, in many ways suggest we are working from a low base and much more is required to achieve the intent of the National Disability Strategy 2010-2020 (Australian Government, 2010). Despite a greater focus on 'community engagement', it is disappointing that the social inclusion of people with disabilities in Australia, as indicated in the published research, is evidenced by deinstitutionalisation, changes in the nature of paid support, and the conceptualisation of meaningful roles as employees or consumers. Indeed, these gains are important but none of these roles are necessarily end-user defined, and arguably reflects how society wants people with disabilities to be included. It is therefore hoped that the greater focus on choice and control 
as part of the continuing roll out of the National Disability Insurance Scheme (NDIS) in Australia will enable more active conceptualisations to be reflected in the literature.

The article by Sprod and Norwood reviews the evidence on the effectiveness of assistance dogs in improving outcomes for children with Autism Spectrum Disorders and their families. The article is considered timely, given some previous concerns identified regarding the lack of evidence to support funding of assistance dogs for people with disabilities in Australia, and current efforts to ensure the value of assistance dogs is recognised by the National Disability Insurance Agency and funded accordingly (for example, Change.org, 2017). Despite observing variability in the nature and quality of the available studies and acknowledging the limitations of the review, Sprod and Norwood conclude that assistance dog programs have been associated with a range of improvements in outcomes including lower stress, greater sense of safety and confidence to engage publicly for families, and observed improvements in communication and social and motor skills for children. The paper therefore provides an important contribution to the evidence base and may further inform funding/decision-making processes in the Australian context.

Rowe and Wright present a useful insight into identified deficiencies in the provision of sexuality education to young people with intellectual disabilities, based on the results of their literature review. As noted by the authors, these deficiencies exist despite ratification of the United Nations Convention on the Rights of Persons with Disabilities (2008) and much advocacy regarding the rights of people with intellectual disabilities to have access to this education and support. The review notes the need to improve access to and engagement in sexuality education that is appropriate to individual needs, and moreover, that respects and upholds their human rights. The identification of the need to change overly conservative curricula which increase social exclusion risks, and reorient delivery methods, for instance, by incorporating more visual aids, is particularly instructive. Although it is acknowledged that school-based education is the primary setting for the delivery of sexuality education, the findings have implications for the broader health and community-service sectors given the need to better recognise the rights of adolescents with intellectual disabilities, and respond to their unique needs in relation to sexuality and sexual health.

The results of a small Australian study $(n=11)$ exploring the experiences of younger, second generation Samoans in Australia are reported in the paper by Stanley and Kearney. The qualitative study sought to explore the issues associated with how second generation Samoans experience life in Australia in response to identified under-representation in educational and employment outcomes. The results of the content analysis of interview data revealed protective factors exist in relation to cultural identity and social connectedness, however, other interactions with churches, parents and friends were found to constrain opportunities, in particular, educational advancement. Of note, Stanley and Kearney conclude that similar phenomena were observed in New Zealand two decades earlier. In addition to gathering further evidence in the domestic context, this presumably means there are lessons that can be learned from across the Tasman as to how to better support and improve outcomes for second generation Samoans in Australia.

The article by Mahoney and Siyambalapitiya presents the results of a literature review on community-based programs that facilitate the social inclusion of refugees and asylum seekers in Australia. In acknowledging the review's limitations, and emerging evidence base for such programs, the paper identifies some key considerations associated with more effective community-based interventions. The four factors identified will hopefully inform future program development in this area. However, as noted by Mahoney and Siyambalapitiya, we need more rigorous program evaluation data to inform the ongoing development and continuous improvement of community-based programs that seek to promote the social inclusion of refugees and asylum seekers in Australia. 
In the final article of this edition, Mclntyre, Townsend and Cullen discuss the key components of an evidence-based protocol (Guddi) for Aboriginal and Torres Strait Islander people with neurocognitive disabilities and who are homeless or at risk of homelessness. Indeed, the identification of a culturally safe and inclusive practice framework to more effectively respond to the diverse and complex needs of this population, provides a valuable contribution to the literature. As does the identification of where further research is required to inform the continuous improvement of service responses, and ultimately, increase outcomes for Aboriginal and Torres Strait Islander peoples with disabilities who are at increased risk of homelessness.

As we end another year and reflect on key events and changes, we can be certain that more change is inevitable. Nevertheless, and despite some recent gains, it is hard to be as confident that these changes will represents diverse interests and differences in power and privilege without considerable concerted effort. We are ideally positioned however, to influence whose voices are heard in the associated debates, and to ensure decision-making reflects the perspectives of those most affected, the available evidence and practice wisdom. To this end, the Journal of Social Inclusion will be transitioning to a new publishing platform in 2018, and we trust this will enable other contributions, voices and ways of knowing to be shared and valued in the future. We sincerely thank all of our contributors and reviewers for your support and look forward to furthering our exploration of social inclusion issues with you in the new year.

\section{Paul Harris PhD}

Editor

School of Human Services and Social Work

Menzies Health Institute Queensland

Griffith University 


\section{References}

Australian Government. (2010). National Disability Strategy 2010 - $2020 . \quad$ Canberra: Department of Social Services.

Change.org. (2017). 'Assistance Dogs under the NDIS. Why are some people funded but many are being denied?' Retrieved from: https://www.change.org/p/national-disabilityinsurance-scheme-assistance-dogs-under-the-ndis-why-are-some-people-fundedbut-many-are-being-denied

Garside, J. (2017). 'Paradise Papers leak reveals secrets of the world elite's hidden wealth', The Guardian, 6 November, 2017. Retrieved from:

https://www.theguardian.com/news/2017/nov/05/paradise-papers-leak-revealssecrets-of-world-elites-hidden-wealth

Gribbin, C. (2017). 'George Brandis may incorporate human rights treaty into SSM bill to satisfy conservatives', $A B C$ News, 18 November, 2017. Retrieved from: http://www.abc.net.au/news/2017-11-18/brandis-may-incorporate-human-rightstreaty-to-ssm-bill/9164770

Perales, F. (2017). 'SSM: How cognitive ability shapes attitudes on equal rights for same-sex couples', $A B C$ News, 26 September, 2017. Retrieved from:

http://www.abc.net.au/news/2017-09-26/same-sex-marriage-cognitive-ability-linkhilda-survey/8984744

Schoon, I., Cheng, H., Gale, C. R., Batty, G. D., \& Deary, I. J. (2010). 'Social status, cognitive ability, and educational attainment as predictors of liberal social attitudes and political trust', Intelligence, 38 (1): 144-150.

Stuart, R. (2017). 'Lisa Wilkinson: NSW Premier Gladys Berejiklian throws support behind TV presenter over pay dispute', $A B C$ News, 17 October, 2017. Retrieved from: http://www.abc.net.au/news/2017-10-17/lisa-wilkinson-pay-stance-backed-by-nswpremier-berejiklian/9057074 